\title{
(6) OPEN ACCESS \\ An alternative sensor-based method for glucose monitoring in children and young people with diabetes
}

\author{
Julie Edge, ${ }_{1}^{1}$ Carlo Acerini, ${ }^{2}$ Fiona Campbell, ${ }^{3}$ Julian Hamilton-Shield, ${ }^{4}$ \\ Chris Moudiotis, ${ }^{5}$ Shakeel Rahman, ${ }^{6}$ Tabitha Randell, ${ }^{7}$ Anne Smith, ${ }^{8}$ Nicola Trevelyan ${ }^{9}$
}

\begin{abstract}
- Additional material is published online only. To view please visit the journal online (http://dx.doi.org/10.1136/ archdischild-2016-311530). For numbered affiliations see end of article.
\end{abstract}

Correspondence to Dr Julie Edge, Paediatric Endocrinology and Diabetes, Oxford Children's Hospital, Oxford, OX3 9DU, UK; julie. edge@paediatrics.ox.ac.uk

Received 30 June 2016 Revised 19 December 2016 Accepted 22 December 2016 Published Online First 30 January 2017
ABSTRACT
Objective To determine accuracy, safety and
acceptability of the FreeStyle Libre Flash Glucose
Monitoring System in the paediatric population.

Design, setting and patients Eighty-nine study participants, aged 4-17 years, with type 1 diabetes were enrolled across 9 diabetes centres in the UK. A factory calibrated sensor was inserted on the back of the upper arm and used for up to 14 days. Sensor glucose measurements were compared with capillary blood glucose $(B G)$ measurements. Sensor results were masked to participants.

Results Clinical accuracy of sensor results versus BG results was demonstrated, with $83.8 \%$ of results in zone consensus error grid. Overall mean absolute relative difference (MARD) was $13.9 \%$. Sensor accuracy was unaffected by patient factors such as age, body weight, sex, method of insulin administration or time of use (day vs night). Participants were in the target glucose range (3.9-10.0 $\mathrm{mmol} / \mathrm{L}$ ) 50\% of the time (mean

12.1 hours/day), with an average of 2.2 hours/day and 9.5 hours/day in hypoglycaemia and hyperglycaemia, respectively. Sensor application, wear/use of the device and comparison to self-monitoring of blood glucose were rated favourably by most participants/caregivers (84.3-100\%). Five device related adverse events were reported across a range of participant ages.

Conclusions Accuracy, safety and user acceptability of the FreeStyle Libre System were demonstrated for the paediatric population. Accuracy of the system was unaffected by subject characteristics, making it suitable for a broad range of children and young people with diabetes.

Trial registration number NCT02388815. $A$ and $99.4 \%$ of results in zones $A$ and $B$ of the

\section{What is already known on this topic?}

- Achieving, improving and maintaining optimal glycaemic control in the paediatric population is challenging because of wide glucose variability, including detected and undetected hypoglycaemia and hyperglycaemia.

- Type 1 diabetes exchange data indicate that the majority $(>75 \%)$ of children/young people with diabetes do not meet International Society for Paediatric and Adolescent Diabetes/ American Diabetes Association guidelines for glycaemic control (glycated haemoglobin $<58 \mathrm{mmol} / \mathrm{mol}(7.5 \%))$. $^{37} 38$

- Sensor-based glucose monitoring is underused owing to cost and acceptability for children and young people with diabetes.

\section{What this study adds?}

- The FreeStyle Libre System is safe and accurate when used by children and young people with diabetes (4-17 years).

- This new sensor-based glucose monitoring technology, requiring no user calibration, was highly acceptable to participants/caregivers. It is anticipated that the system could support enhanced diabetes management.

- Glycaemic variability data for this UK population of 4-17-year-olds show that these children/young people spent on average approximately $50 \%$ of the time in euglycaemia.

\section{INTRODUCTION}

The benefit of good glycaemic control to complications of diabetes is well recognised and selfmonitoring of glucose levels is central to improving and maintaining good glycaemic control. ${ }^{1} 2$ This can be challenging in children and young people due to unpredictable and increased frequency of food intake, variable patterns of physical activity, increased rates of intercurrent illness, and psychological and hormonal challenges of adolescence; all of which can lead to greater glycaemic variability, wider glycaemic excursions and more frequent hypoglycaemia than seen in adults. ${ }^{3-5}$ Currently, self-monitoring of glucose for children and young people involves a fingerprick, four or more times daily. $^{3} 6$ The burden of self-monitoring of blood glucose (SMBG) for patients is well known, and includes: pain, inconvenience, disturbance for night-time tests and embarrassment. ${ }^{7-9}$

Continuous glucose monitoring (CGM) overcomes some of the burden of SMBG and provides a continuum of glucose data, including visibility of night-time glucose, rather than the discrete snapshots obtained by SMBG. A recent review of data from randomised controlled trials on CGM use in the paediatric population concluded that CGM use is safe and efficacious. ${ }^{10}$ However, CGM use in paediatrics has yielded mixed results on glycaemic control outcomes. Some studies demonstrated 
improved outcomes ${ }^{11-17}$ and associated increased benefit with increased use of CGM. ${ }^{16-19}$ Others showed little difference when comparing outcomes following use of CGM and SMBG; in these the lack of clinical benefit was often attributed to poor adherence to CGM use and reduced sensor wear. ${ }^{4}$ 19-22

CGM is underused in children and young people, perhaps in part due to the lack of compelling evidence of the benefit it may provide. Barriers to CGM use include: sensor insertion on a weekly basis; skin reactions, discomfort/pain at the insertion site; frequent alarms especially at night (often turned off due to alarm fatigue); the need for multiple SMBG tests for calibration; interference with activities; poor sensor-receiver connectivity causing loss of data; high cost and limited reimbursement. ${ }^{4} 19^{23-25}$ It has been proposed that reducing these barriers could lead to increased uptake of continuous sensing by children and young people. ${ }^{25}$

The FreeStyle Libre System (Abbott Diabetes Care) used in this study potentially resolves many of the issues that affect adherence with CGM. It provides comprehensive glucose data (similar to CGM systems), increased sensor wear duration (up to 14 days, increasing the time between sensor applications), and has no requirement for fingerprick calibrations. The reader, which displays glucose results after scanning over the small sensor worn on the back of the arm, does not need to be kept close to the sensor and has no automatic alarms (but can alert the user to hypo/hyperglycaemia and pending excursions when detected following a scan). Scanning can be performed as often as is needed, after each scan the reader displays current sensor glucose, a trend arrow and 8-hour glucose history. The sensor automatically stores glucose data every $15 \mathrm{~min}$. Device software can be used to generate summary glucose reports for review by the patient at home or in clinic with their healthcare professional (HCP). These features were not available during the study; the device was masked to participants and HCPs. The system is designed to replace SMBG testing for self-management of diabetes, except during rapidly changing glucose, to confirm hypoglycaemia, or if symptoms do not match system results. This study is the first to report accuracy, safety and acceptability of the FreeStyle Libre System in children and young people. Accuracy of the blood glucose (BG) feature of the system is not under evaluation here; regulatory approval/Conformité Européenne (European Conformity marking of the device confirms this feature meets the required industry standards for performance. At the time of the study, the device was approved for use by adults; it has subsequently been approved for use with children (with supervision from a caregiver).

\section{METHODS}

This prospective, single arm study was conducted across nine diabetes centres in the UK.

\section{Study participants}

Children and young people aged 4-17 years, with type 1 diabetes (T1D) or type 2 diabetes treated with multiple daily injections (MDI) of insulin or continuous subcutaneous insulin infusion (CSII), and currently testing BG at least two times per day were eligible to participate. Exclusion criteria included: concomitant disease/condition that may compromise patient safety; other labelling prohibitions; currently using a CGM device; and known/suspected allergy to medical grade adhesives. Any potentially eligible patient from the general diabetes population at each study site was invited to participate.

\section{Study design}

Participants attended clinic three times. Adverse events (AEs) were reviewed at every participant contact. Visit 1 included a physical examination, FreeStyle Libre device training, sensor insertion and sensor application questionnaire. Participants wore the sensor (on the back of their upper arm) for up to 14 days and were asked to perform four capillary BG tests daily using the BG strip-port on the reader (FreeStyle Optium test strips, Abbott Diabetes Care), each immediately followed by an interstitial fluid (ISF) glucose sensor measurement (data masked to participants) to allow comparison of results between sensor and BG. Visit 2 (days 5, 6, 7 or 8) was a safety monitoring check-up, data was also uploaded. During the final clinic visit (days 12, 13, 14 or 15), the device was unmasked for subjects to experience its full functionality, sensors were removed (and the site inspected for any adverse reactions), data were uploaded and user questionnaires completed. Three sensor lots were used.

Participants were asked to maintain their pre-existing diabetes self-management plan throughout the study.

The study (NCT02388815) was conducted in compliance with the study protocol and International Conference on Harmonisation Guideline for Good Clinical Practice. Competent authority (MHRA) and ethics approval was obtained and each participant or their caregiver gave written, informed consent prior to participation in the study.

\section{Statistical analyses}

For the primary accuracy end point, it was determined that a minimum sample size of 20 participants was needed to obtain a 95\% CI around an estimate of the percentage of results in zone A of the consensus error grid (CEG) of $\pm 5 \%$. However, a larger sample size was used in order to compare results to a similar study performed with adult participants.

Sensor values were compared with temporally matched (within \pm 5 min) BG values using a number of methods to evaluate overall accuracy of the system: mean absolute relative difference (MARD), median absolute relative difference (median $\mathrm{ARD})$, mean relative difference (MRD), proportion of results within $\pm 1.1 \mathrm{mmol} / \mathrm{L}$ of the $\mathrm{BG}$ value for glucose $<5.55 \mathrm{mmol} / \mathrm{L}$ and within $\pm 20 \%$ of the $\mathrm{BG}$ value for glucose $\geq 5.55 \mathrm{mmol} / \mathrm{L}$ (hereafter \%within1.1/20). Mean absolute difference (MAD) and MARD were used to evaluate accuracy at low and mid to high glucose ranges, respectively. (MARD, median ARD, MRD and MAD are all measures of the average difference between sensor and reference values. MARD and median ARD measure the size but not the direction (higher/lower) of the differences compared with the reference (absolute) as a percentage of the reference value (relative). MAD is similar but just reports the size of the difference (it is not reported as a percentage); this is commonly used to assess accuracy at low glucose levels. MRD measures the size and direction of the difference compared with the reference as a percentage of the reference value.)

CEG analysis, a tool developed to determine clinical accuracy of SMBG systems, was used to quantify the clinical accuracy of the device. ${ }^{26}$ A grid of different zones defines the clinical significance of any difference between test and reference results, as outlined in figure $1 \mathrm{~A}$.

Analysis of variance (ANOVA) and simple linear regression were used to assess whether a range of factors affected sensor accuracy.

Hypoglycaemia/hyperglycaemia alert features were evaluated by assessing concordance of sensor alerts obtained within $\pm 15 \mathrm{~min}$ of $\mathrm{BG}$ results in hypoglycaemic $(<3.9 \mathrm{mmol} / \mathrm{L})$ and 
A

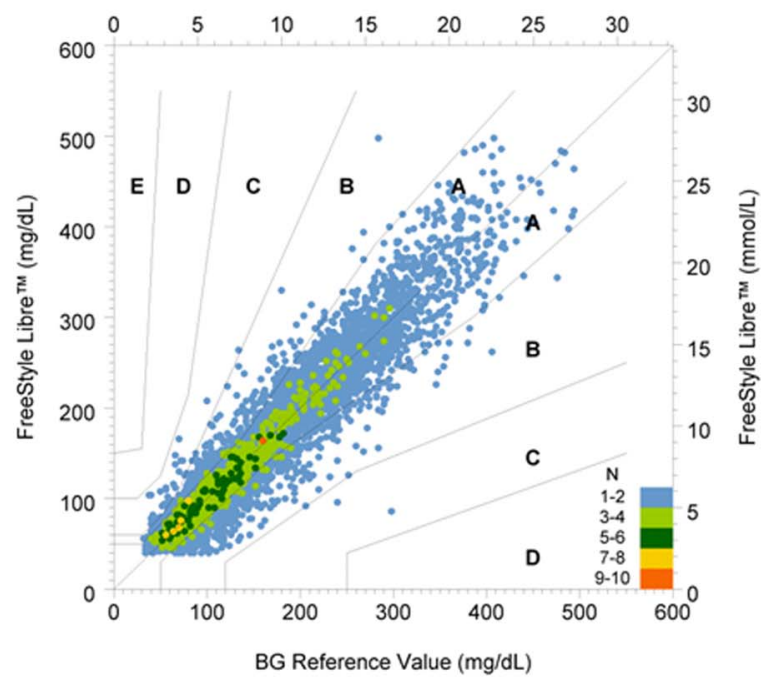

\begin{tabular}{|c|c|c|c|}
\hline CEG Zone & Clinical Significance & $\mathbf{n}$ & $\%$ \\
\hline A & No effect on clinical action & 4601 & 83.8 \\
\hline B & $\begin{array}{c}\text { Altered clinical action, little or no effect on } \\
\text { clinical outcome }\end{array}$ & 857 & 15.6 \\
\hline C & $\begin{array}{c}\text { Altered clinical action, likely to affect } \\
\text { clinical outcome }\end{array}$ & 35 & 0.6 \\
\hline D & $\begin{array}{c}\text { Altered clinical action, could have } \\
\text { significant medical risk }\end{array}$ & 0 & 0.0 \\
\hline E & $\begin{array}{c}\text { Altered clinical action, could have } \\
\text { dangerous consequences }\end{array}$ & 0 & 0.0 \\
\hline & Total & 5493 & 100.0 \\
\hline
\end{tabular}

B

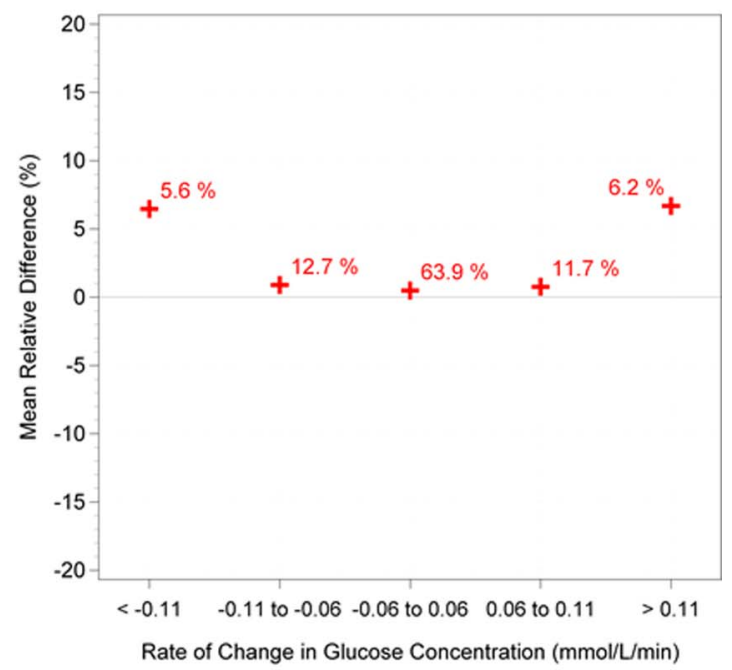

Rates of change in glucose concentration defined by FreeStyle Libre trend arrows:

$\downarrow$ decreasing $>0.11 \mathrm{mmol} / \mathrm{L} / \mathrm{min}$;

$\checkmark$ decreasing between 0.06 and $0.11 \mathrm{mmol} / \mathrm{L} / \mathrm{min}$;

$\rightarrow$ changing $<0.06 \mathrm{mmol} / \mathrm{L} / \mathrm{min}$;

$\nearrow$ increasing between 0.06 and $0.11 \mathrm{mmol} / \mathrm{L} / \mathrm{min}$;

$\uparrow$ increasing $>0.11 \mathrm{mmol} / \mathrm{L} / \mathrm{min}$

Figure 1 Sensor accuracy: (A) Consensus error grid (CEG) analysis comparing FreeStyle Libre sensor results to capillary blood glucose (BG) results. (B) Mean relative difference (MRD) of sensor results to capillary BG at different rates of change in glucose concentration (percentages show proportion of data at each rate of change).

hyperglycaemic $(>13.3 \mathrm{mmol} / \mathrm{L})$ ranges. Rates with pending alerts (ie, those with sensor results within $\pm 10 \%$ of the BG threshold) were also determined.

Measures of glycaemic variability were considered as a secondary end point of the study. Time in range (TIR) was defined as glucose results between $3.9 \mathrm{mmol} / \mathrm{L}$ and $10.0 \mathrm{mmol} / \mathrm{L}$. A hypoglycaemic/hyperglycaemic excursion was defined as $\geq 2$ consecutive results outside the predefined range, corresponding to $>15 \mathrm{~min}$.

Safety outcomes were analysed for all participants who enrolled.

All analyses were performed using SAS software, V.9.2 or later (SAS Institute, Cary, North Carolina, USA).

Missing data have not been imputed in the statistical analysis.

\section{RESULTS}

Eighty-nine participants were enrolled in the study, all with T1D; 50.6\% were male; 56\% used CSII and 44\% used MDI; mean age was 10.4 years, with 24 participants aged 4-7 years, 39 aged $8-12$ years and 26 aged 13-17 years. Duration of diabetes was $4.0 \pm 2.8(0.3,12.2)$ years $(\operatorname{mean} \pm S D(\min , \max ))$ and HbA1c (glycated haemoglobin) was $60 \pm 12(38,90) \mathrm{mmol} / \mathrm{mol}$ (7.6 $\pm 1.1(5.6,10.4) \%)$.

Paired sensor-BG results were not available for 2 participants (1 withdrawal prior to obtaining sensor data, 1 protocol deviation led to no reader BG data); therefore, 87 evaluable participants were included in the accuracy analyses and 88 were included in the glycaemic variability analysis. All 89 participants were included in the safety analyses.

\section{Accuracy performance}

For assessment of sensor accuracy against capillary BG there were 5493 paired sensor-BG results. Overall MARD was $13.9 \%$, median ARD was $10.4 \%$, MRD was $1.7 \%$ and the $\%$ within $1.1 / 20$ was $82.0 \%$. CEG analysis demonstrated $83.8 \%$ of results in zone A and $99.4 \%$ of results in zones A and B (figure 1A). Sensor results were in good agreement with BG resultsDeming regression: slope $=1.03$, intercept $=-0.23 \mathrm{mmol} / \mathrm{L}$, correlation coefficient $=0.95$. For paired results at lower glucose concentrations, with $\mathrm{BG}<5.55 \mathrm{mmol} / \mathrm{L} \quad(\mathrm{n}=1468)$, MAD was $0.75 \mathrm{mmol} / \mathrm{L}$; for paired results at higher glucose concentrations, BG 5.55-10.0 mmol/L $(n=2090)$, MARD was $13.5 \%$; and $B G>10.0 \mathrm{mmol} / \mathrm{L}(\mathrm{n}=1935)$, MARD was $10.6 \%$.

In some sensor systems, a lag is evident between BG and sensor results, such that sensor results are higher than BG results when glucose is decreasing and lower than BG results when glucose is increasing. ${ }^{27}$ This trend (sensor results higher/ lower than BG when glucose is decreasing/increasing) was not evident with the FreeStyle Libre System (figure 1B), demonstrating that there is little 'lag' effect.

There were no statistically significant differences in accuracy detected (ANOVA) for sex $(\mathrm{p}=0.951)$, method of insulin administration $(p=0.640)$, sensor lot $(p=0.135)$ or daytime versus night-time use $(p=0.909)$, as the percentage of results within CEG zone A were similar for the subgroups. Accuracy was also not significantly influenced by age or body weight-the regression slopes (for percentage within CEG zone A vs participant age and weight) were not significantly different from zero $(p=0.133$ and $p=0.284$, respectively).

The sensor detected hypoglycaemia (when capillary BG $<3.9 \mathrm{mmol} / \mathrm{L})$ on $70 \%(438 / 622)$ of occasions, increasing to 
$84 \%$ when pending alerts (sensor results within $10 \%$ of the hypoglycaemic threshold) were included. For the $30 \%$ of occasions where hypoglycaemia measured in capillary testing was not detected by the sensor, further analysis of those results for clinical significance using the CEG indicates that 164 were in zones A and B (clinically acceptable) and 20 were in zone C (altered clinical action-likely to affect clinical outcome). The sensor detected hyperglycaemia (when $\mathrm{BG}>13.3 \mathrm{mmol} / \mathrm{L}$ ) on $85 \%$ of occasions, increasing to $94 \%$ when pending alerts were included $(n=999)$.

\section{Glycaemic variability}

Sensor data collected during the study were used to retrospectively determine glycaemic variability of participants during their time in the study (table 1). Participants were in euglycaemia (3.9-10.0 $\mathrm{mmol} / \mathrm{L}) \sim 50 \%$ of the time; this was the same through day and night, and for both methods of insulin administration. The relationship of TIR to HbA1c is similar for older and younger participants $(p=0.229$ and 0.297 for slope and intercept, respectively, figure 2). On average, participants spent 2.2 hours/day and 9.6 hours/day in hypoglycaemia ( $<3.9 \mathrm{mmol} /$ $\mathrm{L})$ and hyperglycaemia (>10.0 mmol/L), respectively. The breakdown of glucose excursions through daytime and night-time periods and for participants using CSII and MDI is shown in table 1 .

Comparison of glycaemic variability observed in this study to that reported for other studies is made in the online supplementary material.

\section{User acceptability}

Study participants and/or their caregivers rated their experience with the system on a scale of 0 (strongly agree) to 4 (strongly disagree). Statements about sensor application (84.3-92.1\%), sensor wear and use (87.2-100\%), comparing use to SMBG (85.4-97.5\%) and the device itself (68.3-96.3\%) were rated favourably ( 0 or 1 ) by most respondents. Figure 3 summarises responses by sex, and shows the system was perceived similarly by both sexes.

\section{Safety}

One participant had a serious AE that was not related to the study or device (pain and lack of feeling in leg). Five device related AEs were reported in total from five $(6 \%)$ participants, aged 6, 9, 10, 12 and 15 years: allergic reaction, blister, pink mark/scabbing and abrasion on sensor removal $(n=2)$ - four were mild, one was moderate, all were resolved at study completion.

Site exams performed for all sensor insertions checked for anticipated AEs associated with sensor application or insertion sites-moderate erythema was observed on $11.6 \%$ of occasions, mild erythema and pain $13.6 \%$ and $4.1 \%$, respectively, and mild instances of bleeding, bruising, itching and oedema were each on $<3 \%$ of occasions. There were no trends in rate of anticipated AEs, including erythema, with age.

\section{DISCUSSION}

This study was the first to evaluate performance and usability of the FreeStyle Libre System in children and has demonstrated good agreement between sensor and BG results. The system is unique among ISF glucose monitoring sensors in that it can be worn for up to 14 days and does not require user calibration. Comparison of accuracy data from this study to that from other paediatric studies using ISF glucose sensors demonstrated that the factory calibrated system provided similar accuracy to systems requiring daily fingerprick calibrations (table 2). The lack of user calibration eliminates potential

Table 1 Average time in key glycaemic ranges

\begin{tabular}{|c|c|c|c|c|c|c|}
\hline & & \multirow[b]{2}{*}{ Overall } & \multicolumn{2}{|l|}{ Time of day } & \multicolumn{2}{|c|}{ Insulin administration } \\
\hline & & & Daytime $(6: 00-22: 00)^{*}$ & Night-time $(22: 00-6: 00) \dagger$ & CSII & MDI \\
\hline $\mathrm{n}$ (participants) & & 88 & 88 & 87 & 50 & 38 \\
\hline \multicolumn{7}{|l|}{ Sensor glucose, $\mathrm{mmol} / \mathrm{L}$} \\
\hline Mean (SD) & & $9.7(2.0)$ & $9.9(2.1)$ & $9.2(2.4)$ & $9.8(2.0)$ & $9.6(1.9)$ \\
\hline \multicolumn{7}{|c|}{ Time in range, hypoglycaemia and hyperglycaemia, hours per day ( ${ }^{*}$ per day=16-hour period; tper day=8-hour period) } \\
\hline $3.9-10 \mathrm{mmol} / \mathrm{L}$ & $\begin{array}{l}\text { mean }(\mathrm{SD}) \\
\min , \max \end{array}$ & $\begin{array}{l}12.1(3.7) \\
3.6,21.0\end{array}$ & $\begin{array}{l}8.1(2.6) \\
2.7,14.3\end{array}$ & $\begin{array}{l}4.1(1.5) \\
0.8,7.7\end{array}$ & $\begin{array}{l}12.1(3.6) \\
4.2,21.0\end{array}$ & $\begin{array}{l}12.2(3.8) \\
3.6,20.0\end{array}$ \\
\hline$<3.9 \mathrm{mmol} / \mathrm{L}$ & $\begin{array}{l}\text { mean (SD) } \\
\text { min, max }\end{array}$ & $\begin{array}{l}2.2(2.2) \\
0.0,13.5\end{array}$ & $\begin{array}{l}1.2(1.3) \\
0.0,9.0\end{array}$ & $\begin{array}{l}1.0(1.0) \\
0.0,5.7\end{array}$ & $\begin{array}{l}2.0(1.6) \\
0.1,6.5\end{array}$ & $\begin{array}{l}2.6(2.8) \\
0.0,13.5\end{array}$ \\
\hline$<3.0 \mathrm{mmol} / \mathrm{L}$ & $\begin{array}{l}\text { mean (SD) } \\
\text { min, } \max \end{array}$ & $\begin{array}{l}0.9(1.6) \\
0.0,10.5\end{array}$ & $\begin{array}{l}0.4(0.9) \\
0.0,7.0\end{array}$ & $\begin{array}{l}0.5(0.7) \\
0.0,4.8\end{array}$ & $\begin{array}{l}0.7(0.9) \\
0.0,3.4\end{array}$ & $\begin{array}{l}1.3(2.2) \\
0.0,10.5\end{array}$ \\
\hline$>10.0 \mathrm{mmol} / \mathrm{L}$ & $\begin{array}{l}\text { mean (SD) } \\
\text { min, max }\end{array}$ & $\begin{array}{l}9.6(4.2) \\
0.0,19.5\end{array}$ & $\begin{array}{l}6.7(2.9) \\
0.0,13.1\end{array}$ & $\begin{array}{l}2.9(1.8) \\
0.0,7.2\end{array}$ & $\begin{array}{l}9.9(4.4) \\
0.4,19.5\end{array}$ & $\begin{array}{l}9.2(3.9) \\
0.0,15.4\end{array}$ \\
\hline$>13.3 \mathrm{mmol} / \mathrm{L}$ & $\begin{array}{l}\text { mean }(S D) \\
\text { min, } \max \end{array}$ & $\begin{array}{l}5.2(3.4) \\
0.0,14.1\end{array}$ & $\begin{array}{l}3.8(2.5) \\
0.0,10.2\end{array}$ & $\begin{array}{l}1.5(1.3) \\
0.0,5.3\end{array}$ & $\begin{array}{l}5.3(3.5) \\
0.0,14.1\end{array}$ & $\begin{array}{l}5.1(3.3) \\
0.0,11.6\end{array}$ \\
\hline \multicolumn{7}{|c|}{ Frequency of hypoglycaemic and hyperglycaemic events per day (24 hours) } \\
\hline$<3.9 \mathrm{mmol} / \mathrm{L}$ & mean (SD) & $1.3(1.0)$ & $1.0(0.8)$ & $0.5(0.4)$ & $1.2(0.9)$ & $1.4(1.0)$ \\
\hline$<3.0 \mathrm{mmol} / \mathrm{L}$ & mean $(S D)$ & $0.6(0.8)$ & $0.4(0.6)$ & $0.3(0.3)$ & $0.5(0.4)$ & $0.7(1.1)$ \\
\hline$>10.0 \mathrm{mmol} / \mathrm{L}$ & mean $(S D)$ & $2.6(0.8)$ & $2.3(0.7)$ & $0.9(0.5)$ & $2.7(0.8)$ & $2.6(0.8)$ \\
\hline$>13.3 \mathrm{mmol} / \mathrm{L}$ & mean (SD) & $1.8(0.8)$ & $1.5(0.7)$ & $0.6(0.4)$ & $1.8(0.8)$ & $1.8(0.9)$ \\
\hline \multicolumn{7}{|l|}{ Overall glucose variability } \\
\hline $\mathrm{SD}, \mathrm{mmol} / \mathrm{L}$ & & $4.5(1.1)$ & 4.5 (1.1) & $4.0(1.1)$ & $4.4(0.9)$ & $4.6(1.2)$ \\
\hline $\begin{array}{l}\text { Coefficient of variation } \\
\text { (subject level), \% }\end{array}$ & & $46.5(7.8)$ & $45.7(8.0)$ & $43.6(9.6)$ & $45.2(7.7)$ & $48.2(8.1)$ \\
\hline
\end{tabular}

CSII, continuous subcutaneous insulin infusion; MDI, multiple daily injection. 


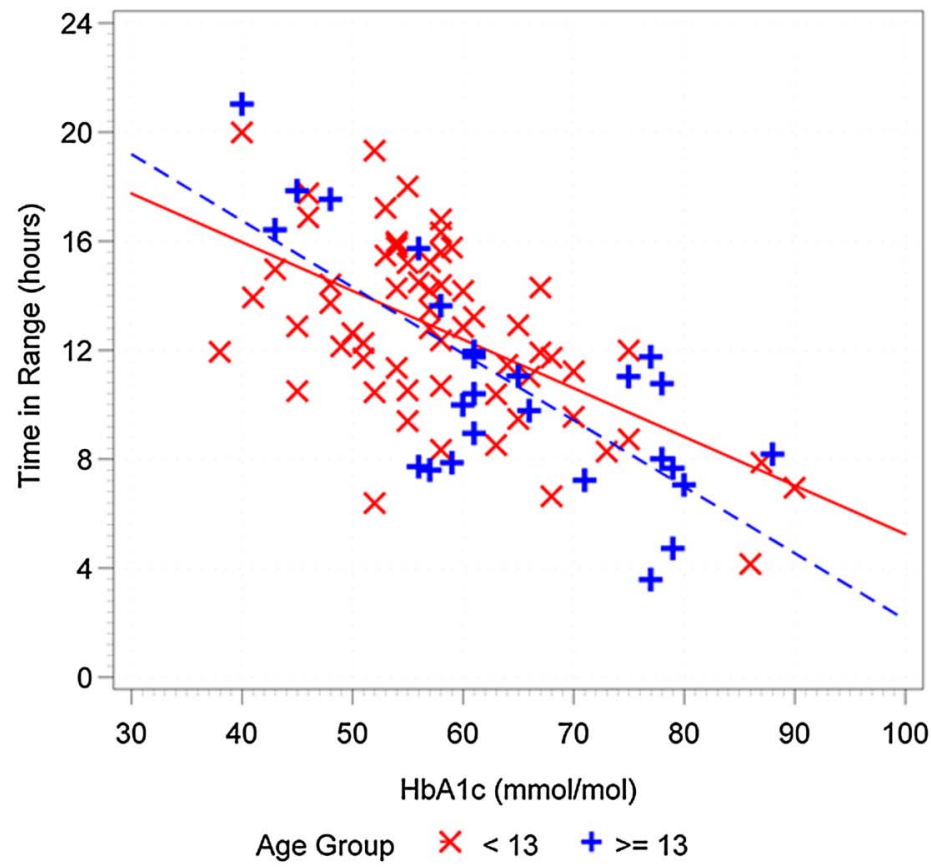

\section{$\underline{\text { Regression statistics }}$}

$<13$ years: $\mathrm{TIR}=27.2113-1.9369 \times \mathrm{HbA} 1 \mathrm{C}$

$\geq 13$ years: $\mathrm{TIR}=32.1350-2.6536 \times \mathrm{HbA} 1 \mathrm{C}$

Slope and intercept for the different age groups was not significantly different, $\mathrm{p}=0.229$ and 0.297 , respectively.

Figure 2 Time in range versus participant glycated haemoglobin ( $\mathrm{HbA1c})$.

Girls

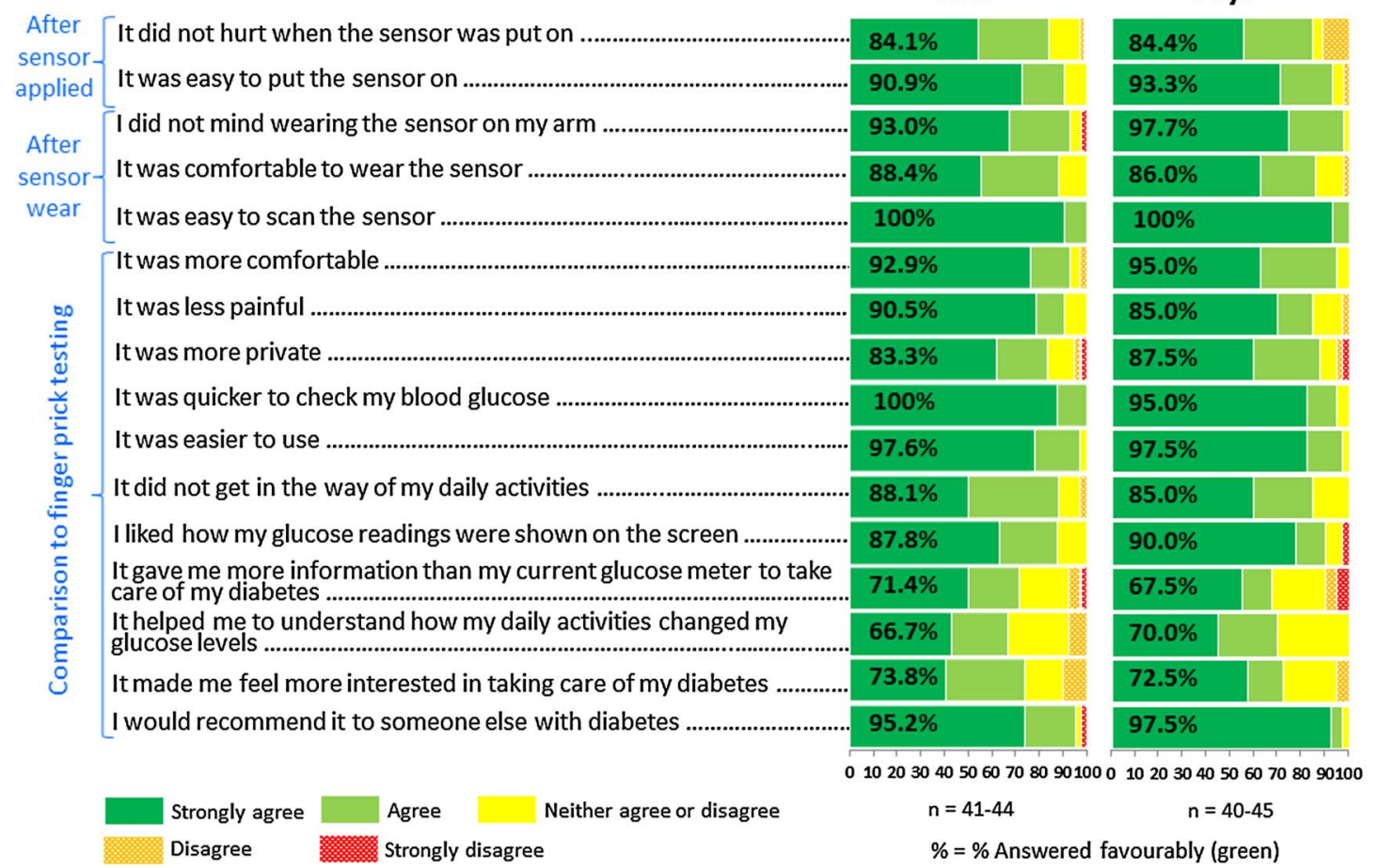

Figure 3 User acceptability with paediatric population (participant and caregiver responses to user questionnaires).

variations in sensor systems that may be introduced through errors in BG results used for calibration, calibration at inappropriate times (during rapidly changing glucose), missing calibrations or use of sensor rather than BG values for calibration. ${ }^{31-33}$

Comparison of results from this study to those from a study where adults used the system ${ }^{34}$ shows: MARD versus capillary BG of $13.9 \%$ and $11.4 \%$; percentage in CEG zone A of $83.8 \%$ and $86.7 \%$; and percentage in CEG zones $\mathrm{A}$ and $\mathrm{B}$ of $99.4 \%$ and $99.7 \%$, in children and adults, respectively. This trend is similar to that reported for other ISF systems: Dexcom G4 Platinum had MARD versus capillary BG of $15 \%$ and $14.0 \%$ in children and adults, respectively. ${ }^{4} 35$ Similarly, Dexcom G4 Platinum with software 505 algorithm had MARD versus capillary BG of $13 \%$ and $11.3 \%$ in children and adults, respectively. 45

This study has confirmed that sensor accuracy is robust to patient characteristics such as age, body weight, method of 
Table 2 Comparison of accuracy for factory calibrated and user calibrated sensor systems

\begin{tabular}{|c|c|c|c|c|c|}
\hline \multirow[b]{2}{*}{ Accuracy measure } & \multirow{2}{*}{$\begin{array}{l}\text { Factory calibrated } \\
\text { FreeStyle Libre }\end{array}$} & \multicolumn{4}{|c|}{ Require daily fingerprick calibrations } \\
\hline & & Glucoday $^{28}$ & Medtronic REALTime 2930 & Dexcom G4 Platinum ${ }^{4}$ & $\begin{array}{l}\text { Dexcom G4 Platinum with } \\
\text { software } 505 \text { algorithm }{ }^{4}\end{array}$ \\
\hline Mean absolute relative difference, $\%$ & 13.9 & 13.9 & $18.0,19.0$ & 15 & 13 \\
\hline $\begin{array}{l}\text { Percentage of results in } \\
\text { zone } A \text { of CEG }\end{array}$ & 83.8 & NA & NA, 66.7 & 80 & 86 \\
\hline Percentage of results in zones $A$ and $B$ of CEG & 99.4 & 98.6 & $94.5,92.3$ & 99 & 100 \\
\hline
\end{tabular}

CEG, consensus error grid; NA, not available.

insulin administration and sex. Accuracy of the system along with its robustness to differing patient characteristics, are sufficient to recommend its use to paediatric patients as support in optimising their glycaemic control. The study identified that there were 20/622 occasions where hypoglycaemia measured in capillary testing was not detected by the sensor and CEG analysis identified that there may be altered clinical action based on the sensor result. The product labelling advises patients to use a BG meter to check the sensor result if symptoms do not match the sensor result.

This study, providing the first glucose variability data for a paediatric population in the UK, and others, 71314172136 show there is significant opportunity to improve glycaemic control in children and young people with diabetes. Several studies have associated improved outcomes with increased sensor wear. ${ }^{16-19}$ A sensor with a longer wear period, that does not require fingerprick calibration, may support more frequent sensor use, and thus help improve clinical outcomes in children and young people.

SMBG provides single, intermittent results, which may not capture intervals of extreme variability or nocturnal events. In comparison, the system displays the current glucose result, the last 8 hours of glucose data (including night-time results without any disturbance to the child) and trend information when the sensor is scanned-providing significantly more data to guide treatment for this challenging population than routine SMBG.

This study has demonstrated safety and user acceptability of the system. Device related AEs occurred in 6\% of participants, the same rate was observed in adults. ${ }^{34}$ The AEs were reported by participants aged 6-15 years, and thus were not concentrated in a particular age group. Anticipated sensor application/insertion site symptoms (pain, bleeding, bruising, erythema, itching, oedema) were reported in $44 \%$ of participants (63\% of which were mild in severity), this is similar to the rate observed in adults, ${ }^{34}$ where $36 \%$ of participants experienced skin issues $(p=0.337)$. Erythema was the symptom noted most frequently and, as with other anticipated AEs, was not associated with particular age groups. Despite these symptoms, results of the user questionnaires were similar for boys and girls and were largely favourable, culminating in $96.3 \%$ of respondents stating they would recommend the system to someone else with diabetes.

A limitation of this study is the single body site used. Additional studies are needed to determine suitability of additional body sites for sensor wear and longer-term studies are needed to evaluate whether this system can provide improved adherence with sensor wear and improved glycaemic outcomes with continued use over time. Exploring alternate reference methods and more detailed analysis of the glycaemic variability data using subgroups (eg, age) may be of interest.

\section{CONCLUSIONS}

This prospective study has clearly demonstrated the accuracy, safety and user acceptability of the FreeStyle Libre System for the paediatric population. Accuracy was unaffected by subject characteristics, making the system potentially suitable for a broad range of children and young people with diabetes. It is anticipated that the provision of comprehensive glucose data for up to 14 days, from a system that is easy to use, with reduced pain and burden for the user since there is no requirement for fingerprick calibration, could support enhanced diabetes management. Further studies are needed to determine whether improved outcomes can be achieved with prolonged use of the system.

\section{Author affiliations}

${ }^{1}$ Department of Paediatric Endocrinology and Diabetes, Oxford Children's Hospital, Oxford, UK

${ }^{2}$ The Weston Centre for Childhood \& Adolescent Diabetes and Endocrinology, Addenbrooke's Hospital, Cambridge, UK

${ }^{3}$ Multi Speciality Out-Patients Department, Leeds Children's Hospital, Leeds Teaching Hospitals, Leeds, UK

${ }^{4}$ Department of Paediatric Diabetes and Endocrinology, Bristol Royal Hospital for Children, Bristol, UK

${ }^{5}$ Department of Paediatric Diabetes and Endocrinology, Royal Devon and Exeter NHS Foundation Trust, Exeter, UK

${ }^{6}$ Department of Paediatric Diabetes and Endocrinology, Harrogate District Hospital, Harrogate, UK

${ }^{7}$ Department of Paediatric Diabetes and Endocrinology, Nottingham University Hospitals NHS Trust, Nottingham, UK

${ }^{8}$ Department of Paediatric Diabetes and Endocrinology, Northampton General Hospital, Northampton, UK

${ }^{9}$ Southampton Children's Hospital, Southampton General Hospital, Southampton, UK

Acknowledgements The authors thank all the patients, caregivers and study staff for their participation and support in the study. The authors also thank Dan Bonnick and Mark Lazarus for their statistical support and Claire Brannan for her technical writing support (all from Abbott Diabetes Care).

Contributors Abbott Diabetes Care planned and funded (including provision of devices) the study described in the article. Prior to initiation of the study, site clinical staff were trained in use of the device by clinical staff from Abbott Diabetes Care. The study was conducted at the following sites: Oxford Children's Hospital, principal investigator: JE, Addenbrooke's Hospital, principal investigator: CA, Leeds Children's Hospital, principal investigator: FC, Bristol Royal Hospital for Children, principal investigator: JH-S, Royal Devon and Exeter NHS Foundation Trust, principal investigator: CM, Harrogate District Hospital, principal investigator: SR, Nottingham University Hospitals NHS Trust, principal investigator: TR, Northampton General Hospital, principal investigator: AS, Southampton General Hospital, principal investigator: NT. The Paediatric Diabetes and Endocrinology Team, in particular Loraine Bunton and Jane Bowen-Morris, at Oxford Children's Hospital aided in the design of the participant information sheets prior to submission to the ethics board. The NIHR Young Persons' Advisory Group, Liverpool Regional Group, critically reviewed the design and content of participant information sheets prior to submission to the ethics board. Study staff at each site contributed to data collection. The principal investigator at each site contributed to the writing of the original article.

Funding Abbott Diabetes Care. 
Competing interests All authors' institutions received financial support from Abbott Diabetes Care to conduct the clinical trial. TR received honoraria/fees for consulting from Abbott Diabetes Care outside of the submitted work. The study sponsor (Abbott Diabetes Care) designed the study protocol in collaboration with the principal investigator and provided all study materials. The sponsor was involved in collecting data and reporting results. The sponsor also gave approval to submit for publication. The corresponding author had full access to all the data in the study and, together with all authors, had final responsibility for the decision to submit for publication

Ethics approval West Midland, Edgbaston Committee.

Provenance and peer review Not commissioned; externally peer reviewed.

Open Access This is an Open Access article distributed in accordance with the Creative Commons Attribution Non Commercial (CC BY-NC 4.0) license, which permits others to distribute, remix, adapt, build upon this work non-commercially, and license their derivative works on different terms, provided the original work is properly cited and the use is non-commercial. See: http://creativecommons.org/ licenses/by-nc/4.0/

\section{REFERENCES}

1 Diabetes Control and Complication Trial Research Group. Effect of intensive diabetes treatment on the development and progression of long-term complications in insulin-dependent diabetes mellitus. N Engl J Med 1993;329:977-86.

2 Diabetes Control and Complication Trial Research Group. Effect of intensive diabetes treatment on the development and progression of long-term complications in adolescents with insulin dependent diabetes mellitus: diabetes control and complications trial. J Pediatr 1994;125:177-88

3 Gregory JW. What are the main research findings during the last 5 years that have changed my clinical practice in diabetes medicine? Arch Dis Child 2012;97:436-9.

4 Laffel L. Improved accuracy of continuous glucose monitoring systems in pediatric patients with diabetes mellitus: results from two studies. Diabetes Technol Ther 2016; 18(Suppl 2):S23-33.

5 International Diabetes Federation. Global IDF/ISPAD guideline for diabetes in childhood and adolescence, 2011.

6 Hathout E, Lakey J, Shapiro J. Islet transplant: An option for childhood diabetes. Arch Dis Child 2003;88:591-4.

7 Hall RF, Joseph DH, Schwartz-Barcott D. Overcoming obstacles to behaviour change in diabetes self-management. Diabetes Educ 2003;29:303-11.

8 Wagner J, Malchoff MD, Abbott G. Invasiveness as a barrier to self-monitoring of blood glucose in diabetes. Diabetes Technol Ther 2005;7:612-19.

9 Whittemore R, Jaser S, Chao A, et al. Psychological experience of parents of children with type 1 diabetes: a systematic mixed-studies review. Diabetes Educ 2012;38:562-79.

10 Dovc K, Bratina N, Battelino T. A new horizon for glucose monitoring. Horm Res Paediatr 2015;83:149-56.

11 Bloomgarden DK, Freeman J, DeRobertis E. Early patient and clinician experiences with continuous glucose monitoring. Diabetes Spectr 2008;21:128-33.

12 Battelino $\mathrm{T}$, Moshe $\mathrm{P}$, Bratina N, et al. Effect of continuous glucose monitoring on hypoglycemia in type 1 diabetes. Diabetes Care 2011;34:795-800.

13 The Juvenile Diabetes Research Foundation Continuous Glucose Monitoring Study Group. The effect of continuous glucose monitoring in well-controlled type 1 diabetes. Diabetes Care 2009;32:1378-83.

14 Buckingham B, Beck RW, Tamborlane WV, et al., Diabetes Research in Children Network (DirecNet) Study Group. Continuous glucose monitoring in children with type 1 diabetes. J Pediatr 2007:151:388-93.

15 Diabetes Research in Children Network (DirecNet) Study Group. FreeStyle Navigator Continuous Glucose Monitoring System use in children with type 1 diabetes using glargine-based multiple daily dose regimens. Diabetes Care 2008;31:525-7.

16 Rasbach LE, Volkening LK, Markowitz JT, et al. Youth and parent measures of self-efficacy for continuous glucose monitoring: Survey psychometric properties. Diabetes Technol Ther 2015;17:327-34.
17 The SWITCH study group. The use and efficacy of continuous glucose monitoring in Type 1 diabetes treated with insulin pump therapy: A randomised controlled trial. Diabetologia 2012;55:3155-62.

18 Chase PH, Beck RW, Xing D, et al. Continuous glucose monitoring in youth with type 1 diabetes: 12-Month follow-up of the Juvenile Diabetes Research Foundation continuous glucose monitoring randomized trial. Diabetes Technol Ther 2010;12:507-15

19 Rachmiel M, Landau Z, Boaz $M$, et al. The use of continuous glucose monitoring systems in a pediatric population with type 1 diabetes mellitus in real-life settings: The AWeSoMe study group experience. Acta Diabetol 2015;52:323-9.

20 The Juvenile Diabetes Research Foundation Continuous Glucose Monitoring Study Group. Continuous glucose monitoring and intensive treatment of type 1 diabetes. N Engl J Med 2008;359:1464-76.

21 The Juvenile Diabetes Research Foundation Continuous Glucose Monitoring Study Group. Effectiveness of continuous glucose monitoring in a clinical care environment. Diabetes Care 2010;33:17-22.

22 Mauras N, Beck R, Xing $D$, et al. A randomized clinical trial to assess the efficacy and safety of real-time continuous glucose monitoring in the management of type 1 diabetes in young children aged 4 to $<10$ Years. Diabetes Care 2012;35: 204-10.

23 T1D Exchange Clinic Network. Real-time continuous glucose monitoring among participants in the T1D exchange clinic registry. Diabetes Care 2014;37:2702-9.

24 Diabetes Research in Children Network (DirecNet) Study Group. Prolonged use of continuous glucose monitors in children with type 1 diabetes on continuous subcutaneous insulin infusion or intensive multiple-daily injection therapy. Pediatr Diabetes 2009;10:91-6.

25 Rodbard D. Continuous glucose monitoring: a review of success, challenges, and opportunities. Diabetes Technol Ther 2016;18(Suppl 2):S3-13.

26 Parkes JL, Slatin SL, Pardo S, et al. A new consensus error grid to evaluate the clinical significance of inaccuracies in the measurement of blood glucose. Diabetes Care 2000;23:1143-8.

27 Cengiz E, Tamborlane WV. A tale of two compartments: interstitial versus blood glucose monitoring. Diabetes Technol Ther 2009;11(Suppl 1):S11-16.

28 Meschi F, Bonfanti R, Rigamonti A, et al. Patients' evaluation of nocturnal hypoglycaemia with GlucoDay continuous glucose monitoring in paediatric patients. Acta Diabetol 2010;47:295-300.

29 Mastrototaro J, Shin J, Marcus A, et al. The accuracy and efficacy of real-time continuous glucose monitoring sensor in patients with type 1 diabetes. Diabetes Technol Ther 2008;10:385-90.

30 Medtronic Guardian Real-Time Continuous Glucose Monitoring System User Guide. Ref: 6025254-019_c.

31 Garcia A, Hamilton T, Bohnett L, et al. Effect of self-monitoring of blood glucose calibration errors on performance of the Dexcom G4 continuous glucose monitoring system. J Diabetes Sci Technol 2013;7:A47-8.

32 Block J. Continuous glucose monitoring: changing diabetes behaviour in real time and retrospectively. J Diabetes Sci Technol 2008:2:484-9.

33 Klonoff DC. Continuous glucose monitoring-roadmap for $21^{\text {st }}$ century diabetes therapy. Diabetes Care 2005:28:1231-9.

34 Bailey T, Bode BW, Christiansen MP, et al. The performance and usability of a factory-calibrated flash glucose monitoring system. Diabetes Technol Ther 2015:17:787-94.

35 Dexcom G4 Platinum Continuous Glucose Monitoring System User's Guide. Ref: LBL012528 Rev 03 MT22690.

36 Tansey M, Beck R, Ruedy K, et al., Diabetes Research in Children Network (DirecNet) Study Group. Persistently high glucose levels in young children with type 1 diabetes. Pediatr Diabetes 2016;17:93-100.

37 Wood JR, Miller KM, Maahs DM, et al. Most youth with type 1 diabetes in the T1D Exchange Clinic Registry do not meet American Diabetes Association or International Society for Pediatric and Adolescent Diabetes clinical guidelines. Diabetes Care 2013;36:2035-7

38 Miller KM, Foster NC, Beck RW, et al. Current state of type 1 diabetes treatment in the US: Updated data from the T1D exchange clinic registry. Diabetes Care 2015:38:971-8 